\title{
Rapid Dopamine Signaling Differentially Modulates Distinct Microcircuits within the Nucleus Accumbens during Sucrose-Directed Behavior
}

\author{
Fabio Cacciapaglia, ${ }^{1,2}$ R. Mark Wightman, ${ }^{1,3}$ and Regina M. Carelli ${ }^{2,3}$ \\ Departments of ${ }^{2}$ Chemistry and ${ }^{2}$ Psychology, and ${ }^{3}$ Neuroscience Center, University of North Carolina, Chapel Hill, North Carolina 27599
}

The mesolimbic dopamine projection from the ventral tegmental area (VTA) to the nucleus accumbens (NAc) is critical in mediating reward-related behaviors, but the precise role of dopamine in this process remains unknown. We completed a series of studies to examine whether coincident changes occur in NAc cell firing and rapid dopamine release during goal-directed behaviors for sucrose and if so, to determine whether the two are causally linked. We show that distinct populations of NAc neurons differentially encode sucrose-directed behaviors, and using a combined electrophysiology/electrochemistry technique, further show that it is at those locations that rapid dopamine signaling is observed. To determine causality, NAc cell firing was recorded during selective pharmacological inactivation of dopamine burst firing using the NMDA receptor antagonist, AP-5. We show that phasic dopamine selectively modulates excitatory but not inhibitory responses of NAc neurons during sucrose-seeking behavior. Thus, rapid dopamine signaling does not exert global actions in the NAc but selectively modulates discrete NAc microcircuits that ultimately influence goal-directed actions.

\section{Introduction}

The nucleus accumbens (NAc) is critically involved in learning associations between cues that predict reward and reward procurement. Given its anatomical organization, the NAc is considered a limbic-motor interface (Mogenson et al., 1980) translating information about rewards into appropriate behavioral responses to obtain them. Using electrophysiological recordings we have shown that NAc neurons encode the critical features of reward-seeking behavior. Subsets of NAc neurons exhibit patterned changes (increases and/or decreases) in firing rate within seconds of lever pressing for water/food (Carelli et al., 2000, Carelli, 2002), intracranial self-stimulation (ICSS) (Cheer et al., 2005), cocaine self-administration (Carelli et al., 1993; Hollander and Carelli, 2005), and presentation of reward-associated cues (Day et al., 2006). Further, our electrochemical studies revealed increases in NAc dopamine release that occur on the same rapid timescale as NAc cell firing during similar behavioral tasks (Phillips et al., 2003; Roitman et al., 2004; Cheer et al., 2007; Day et al., 2007; Owesson-White et al., 2008; Jones et al., 2010).

The encoding of goal-directed actions by NAc neurons appears to be dopamine-dependent (Yun et al., 2004); however, the precise causal link between dopamine release and cell firing is

Received March 16, 2011; revised July 21, 2011; accepted Aug. 9, 2011.

Author contributions: R.M.W. and R.M.C. designed research; F.C. performed research; F.C. analyzed data; F.C., R.M.W., and R.M.C. wrote the paper.

This work was supported by NIH Grants DA10900 to R.M.W. and DA017318 to R.M.C. We thank Robert Wheeler for assistance with multineuron recording experiments and Michael Saddoris for assistance with the preparation of this manuscript.

Correspondence should be addressed to Regina M. Carelli, Distinguished Professor, Department of Psychology, University of North Carolina, Chapel Hill, CB\#3270 Davie Hall, Chapel Hill, NC 27599. E-mail: rcarelli@unc.edu.

DOI:10.1523/JNEUROSCI.1340-11.2011

Copyright $\odot 2011$ the authors $\quad 0270-6474 / 11 / 3113860-10 \$ 15.00 / 0$ unclear. Previously, we used a combined electrophysiology/electrochemistry technique to simultaneously monitor neuronal activity and dopamine release at the same location during behavior. We showed that rapid dopamine release is primarily observed at sites at which NAc neurons exhibit patterned cell firing during goal-directed actions for ICSS or cocaine (Cheer et al., 2005; Owesson-White et al., 2009). However, coincident activation does not necessarily indicate a causal link. For example, pretreatment with a dopamine D1 receptor antagonist reduced excitatory activity of NAc neurons evoked by VTA stimulation, but had no effect on inhibitory activity in the NAc core (Cheer et al., 2005). Thus, VTA dopamine neurons may differentially modulate NAc cell firing depending upon cell type, location, reward type and ongoing behavior.

Here, we completed a series of studies to examine whether coincident changes occur in NAc cell firing and rapid dopamine release during goal-directed behaviors for 'natural' (sucrose) reward and if so, to determine whether the two are causally linked. First, we used multineuron recording procedures to characterize NAc cell firing during the task since many neurons can be recorded simultaneously. Next, we used our combined electrophysiology/electrochemistry method to sample representative cell types determined above, and examine whether coincident changes occur in dopamine release and NAc patterned activity, similar to prior studies involving other rewards (Cheer et al., 2005, 2007; Owesson-White et al., 2009). Finally, to determine causality, we pharmacologically inactivated the VTA with the NMDA receptor antagonist, AP-5. This procedure enabled a selective decrease in phasic (not tonic) firing of dopamine neurons (Overton and Clark, 1992) supporting the established finding that NMDA receptors control burst firing of dopamine neurons (Johnson et al., 1992; Suaud-Chagny et al., 1992; Chergui et al., 
1993; Deister et al., 2009). We reveal that rapid dopamine signaling operates within a complex microcircuit in the NAc, selectively modulating excitatory but not inhibitory responses of NAc.

\section{Materials and Methods}

Animals. Thirty-three male Sprague Dawley rats weighing 260-330 g were used as subjects. Animals were individually housed with a $12 \mathrm{~h}$ light/dark cycle and maintained at no less than $85 \%$ of preexperimental body weight by food restriction (10 - $15 \mathrm{~g}$ of Purina laboratory chow each day, in addition to $\sim 2.7 \mathrm{~g}$ of sucrose consumed during daily sessions). This regimen was in place for the duration of behavioral testing except during the postsurgery recovery period, when food was given ad libitum. All procedures were performed in accordance with the University of North Carolina at Chapel Hill Institutional Animal Care and Use Committee.

Sucrose self-administration. Sucrose self-administration experiments were conducted in a $43 \times 43 \times 53 \mathrm{~cm}$ operant chamber containing a retractable lever with a cue light above it. The day before the initiation of task training, a single 60 trial magazine session was completed. Rats were then trained to self-administer sucrose pellets during single daily sessions ( $5 \mathrm{~d} /$ week, 60 trials/session). The beginning of the session was signaled by the onset of a house light and white noise. After a variable interval (VI) (initially VI 5-25 s, then gradually increased over $\sim 5-7 \mathrm{~d}$ to VI; 30-60 s), an audiovisual cue (tone/cuelight above lever) was presented and $2 \mathrm{~s}$ later the lever extended into the chamber. Each lever press within $15 \mathrm{~s}$ after lever extension resulted in the delivery of a sucrose pellet ( $45 \mathrm{mg}$ ) into the receptacle, retraction of the lever, and termination of the audiovisual cue. If animals did not press the lever within the $15 \mathrm{~s}$ period, the lever was retracted, the audio-visual cue was terminated, and the variable interval was initiated (Fig. 1). All subjects completed the task (final VI 30-60 s) for 3-5 consecutive days before undergoing surgery.

Surgical procedures. After behavioral training, separate groups of animals underwent surgical procedures for each experiment under ketamine hydrochloride $(100 \mathrm{mg} / \mathrm{kg}, \mathrm{i} . \mathrm{m}$.) and xylazine hydrochloride $(20$ $\mathrm{mg} / \mathrm{kg}$ ) anesthesia. For experiment 1 (multineuron recording), microwire electrode arrays ( 8 wires/array) were permanently implanted bilaterally into the NAc shell $[+1.7 \mathrm{~mm}$ anteroposterior (AP), $\pm 0.8 \mathrm{~mm}$ mediolateral (ML) relative to bregma, and $-6.2 \mathrm{~mm}$ dorsoventral (DV) from brain surface] or core $(+1.7 \mathrm{~mm} \mathrm{AP,} \pm 1.3 \mathrm{~mm}$ ML relative to bregma, and $-6.2 \mathrm{~mm} \mathrm{DV}$ ) as previously described (Jones et al., 2008; Wheeler et al., 2008). For experiment 2 (simultaneous electrochemistry/ electrophysiology), a guide cannula was implanted above the NAc shell $(+1.7 \mathrm{~mm} \mathrm{AP},+0.8 \mathrm{~mm} \mathrm{ML})$ or core $(+1.3 \mathrm{~mm} \mathrm{AP},+1.3 \mathrm{~mm} \mathrm{ML})$ and a bipolar stimulating electrode was placed in the VTA $(-5.2 \mathrm{~mm}$ AP, $+1.0 \mathrm{~mm} \mathrm{ML}$, and $-7.8 \mathrm{DV}$ ) following established procedures (Owesson-White et al., 2009). Another guide cannula for the reference $\mathrm{Ag} / \mathrm{AgCl}$ electrode was placed in the contralateral hemisphere. For experiment 3 (VTA inactivation and electrophysiology), rats were implanted with microwire electrode arrays bilaterally inserted into the NAc (as for the first study), and guide cannulas for microinjection, implanted bilaterally in the VTA. Target coordinates of the VTA injection were as follows: $-5.3 \mathrm{~mm} \mathrm{AP,} \pm 1 \mathrm{~mm}$ ML from bregma, and $-6.8 \mathrm{~mm}$ DV from brain surface (for the inactivation of DA neurons projecting to the NAc shell) and $-4.8 \mathrm{~mm} \mathrm{AP}, \pm 1.5 \mathrm{ML}$ from bregma, and $-6.8 \mathrm{~mm} \mathrm{DV}$ from brain surface at a $6^{\circ}$ angle (for the inactivation of dopamine neurons projecting to the NAc core), as per Ikemoto (2007). Components were secured to the skull with screws and cranioplastic cement and animals received a reminder postsurgery session the day before each recording.

Multineuron recording. In experiment 1, electrophysiological recording procedures were used as described in detail previously (Carelli, 2000; Roitman et al., 2005). Briefly, before the start of the session, rats were placed in the operant chamber and connected to a flexible recording cable attached to a commutator (Med Associates Inc.) which allowed virtually unrestrained movement within the chamber. NAc activity was recorded differentially between each active and the inactive (reference) wire. The reference wire was chosen for an absence of neuronal activity. Online isolation and discrimination was accomplished using a commercially available neurophysiological system (multichannel acquisition

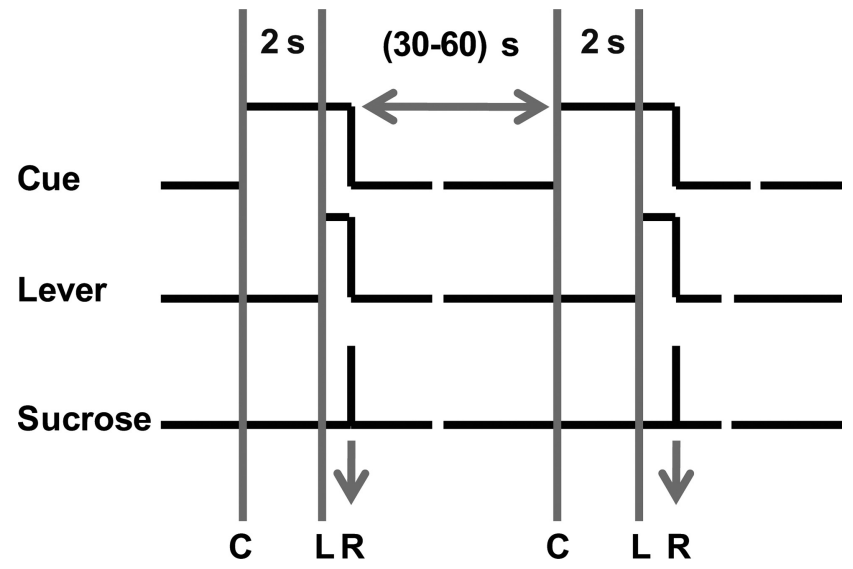

Figure 1. Diagram of the behavioral task. An audiovisual cue (C) was presented on a variable interval $45 \mathrm{~s}$ schedule $(30-60 \mathrm{~s})$. Two seconds later, a lever (L) extended into the chamber. Each lever press (denoted by Rat arrow) resulted in delivery of a sucrose pellet, retraction of the lever, and offset of the audiovisual cue. Missed trials (failure to lever press within $15 \mathrm{~s}$ of lever extension) resulted in retraction of the lever, termination of the audiovisual cue, and no sucrose delivery. Area between vertical gray lines denotes period between cue onset and lever extension.

\section{Table 1. Cell types/numbers across experiments}

\begin{tabular}{lllc}
\hline & Experiment 1 & Experiment 2 & Experiment 3 \\
\hline Number of rats & 10 & 14 & 9 \\
Total number of cells & 79 & 22 & 45 \\
Non-phasic & 26 & 4 & 11 \\
Total phasic & 53 & 18 & 25 \\
$\quad$ Type CE & 12 & 2 & 6 \\
Type Cl & 13 & 8 & 4 \\
Type RE & 13 & 2 & 5 \\
Type RI & 7 & 4 & 5 \\
Type CE +RI & 4 & 0 & 0 \\
$\quad$ Type Cl+RE & 4 & 2 & 5 \\
Contralateral hemisphere (Exp 3) & & & 9 \\
\hline
\end{tabular}

processor, MAP System, Plexon). The identification of multiple neurons on a single wire was accomplished using previously described criteria (Roitman et al., 2005) via template and principal component analysis procedures provided by the neurophysiological software system (MAP system). Cell sorting was completed after the session via principal component analysis in Offline Sorter (Plexon Inc.). Recordings were made during a single 60 trial session.

Simultaneous electrochemistry/electrophysiology recordings. In experiment 2, combined electrophysiological and electrochemical recordings were made as described in detail previously (Cheer et al., 2007; OwessonWhite et al., 2009). Briefly, a carbon-fiber microelectrode was lowered into the NAc shell or core with a locally constructed microdrive (The University of North Carolina at Chapel Hill, Department of Chemistry Instrument shop), after placing an $\mathrm{Ag} / \mathrm{AgCl}$ reference electrode in the contralateral hemisphere. Wires from the reference and stimulating electrodes and a head-stage amplifier connected to the carbon-fiber electrode were routed to a swivel (Med Associates), which allowed free movement of the rat, and then to custom-built amplifiers (Chemistry Department Electronic Facility, University of North Carolina, Chapel Hill) and into a computer interface. A solid-state relay in the head-stage alternated between a current amplifier for voltammetric scans and voltage follower for unit recordings. Both signals were referenced to the $\mathrm{Ag} / \mathrm{AgCl}$ electrode that was connected to ground. Cyclic voltammograms were repeated at $0.2 \mathrm{~s}$ intervals and used a voltage scan from -0.4 to 1.3 to $-1.3 \mathrm{~V}$. The electrode potential was allowed to float during electrophysiological recordings. Measurements were made at sites where single units were isolated and electrical stimulation ( $125 \mu \mathrm{A}$ biphasic pulses, 2 ms per phase, $60 \mathrm{~Hz}, 24$ pulses) evoked detectable dopamine release. However, recordings were only made during sucrose self-administration 
sessions (30 trials/session). After data collection at a given site, the electrode was lowered $\sim 300 \mu \mathrm{m}$ until other unit and release site were found. Recordings were made during 30 trial sessions. Of 14 animals, recordings were made in a single session for 9 animals; for the remaining 5 rats, 2 or 3 recording sessions were made. Task performance was not altered as a function of multiple recordings.

VTA inactivation. In experiment 3 , NAc cell firing was recorded before and during VTA inactivation. Electrophysiological recording procedures were as described for the first study. Before the behavioral session started, an infusion cannula (33 gauge) was gently inserted into the implanted guide, and protruded $1 \mathrm{~mm}$ from the tip of the guide. The cannula was implanted $1 \mathrm{~mm}$ above the injection site and was connected to a syringe pump (Harvard Apparatus). The first microinfusion ( $0.5 \mu \mathrm{l}$ for $60 \mathrm{~s})$ into one side of the VTA consisted of saline $(0.9 \%)$. The needle was removed $60 \mathrm{~s}$ after the end of the infusion and the behavioral session started for 30 trials. Next, on the same day, AP-5 ( $5 \mathrm{nmol}, 0.5 \mu \mathrm{l})$ was microinfused in the same way, followed by completion of another 30 self-administration trials. On the next day the same procedure was repeated in the same animals, but infusions were made in the contralateral VTA (i.e., saline was infused and behavior tested for 30 trials, followed by drug infusion and another 30 trials). NAc cell firing was recorded on both sides of brain following each infusion on each day.

Data analysis. Neural activity was characterized with raster displays and peri-event histograms (PEHs) constructed around cue onset or lever-press. The $10 \mathrm{~s}$ before cue onset or lever press responding was used as a baseline period. Firing rates were calculated for each neuron across a $10 \mathrm{~s}$ window before and after cue onset or the lever-press. Each unit was classified as exhibiting phasic or non-phasic activity. A phasic cell was defined as having at least 2 consecutive bins that were below (for inhibition) or above (for excitation) the $99 \%$ confidence interval threshold described as: baseline firing rate +2.57 (for $99 \%$ confidence interval) $\times \mathrm{SD}$ of baseline. Phasic units were categorized, based on their firing pattern, into one of the following types: cue excitation (CE) or cue inhibition (CI) when the cell firing increased or decreased, respectively, after cue onset; response excitation (RE) or response inhibition (RI) when firing rates increased or decreased, respectively, after the sucrose-reinforced response followed by sucrose retrieval, and multiphasic when the same neuron showed changes in cell firing at both cue onset and lever press/reward retrieval.

Voltammetry data were analyzed \pm 10 s relative to the cue onset or the lever press. A calibration set of cyclic voltammograms of dopamine and $\mathrm{pH}$ changes was obtained in vivo during VTA stimulations that evoked different amounts of release (Heien et al., 2005). This training set was used to perform principal component analysis on data collected as previously described (Heien et al., 2005; Keithley et al., 2010).

Statistics. For experiment 1, cells were classified as phasic based on confidence interval statistics described above. For experiment 2, significant changes in peak dopamine levels relative to cue onset or the response were determined via Students paired $t$ tests. Specifically, the average peak change in dopamine release (within $2 \mathrm{~s}$ following cue onset or the lever press) was statistically compared with the average baseline dopamine concentration (10 s before cue onset) via Student's paired $t$ test. For experiment 3 , a within-subjects repeated-measures ANOVA using the factors of cue (precue versus postcue), drug (AP5 versus saline) and bin (10 $1 \mathrm{~s}$ bins) was used. Significant interactions between these factors was determined by Tukey's HSD test, used to compare firing rates (averaged into $1 \mathrm{~s}$ bins across a $20 \mathrm{~s}$ time window) before and after microinfusion of AP-5. For multiphasic neurons (type CI+RE cells), a within-subjects repeated-measures ANOVA followed by Tukey's HSD test was used to compare the average baseline firing rates to the peak excitation (to the response) and trough inhibition (to the cue) before and after microinfusion of AP-5. Similar ANOVA tests were completed to examine the effects of AP-5 on neural encoding aligned to the operant response, using preresponse versus postresponse as factors (drug and bin factors re- 
mained the same as above), following by Tukey's HSD test to determine specific differences within the interaction. To determine whether AP-5 microinfusion into the VTA affected the behavioral response for sucrose, the average latency to lever press for sucrose following lever extension before and following VTA inactivation was compared with a Student's paired $t$ test. To further examine the relationship between rapid dopamine release and NAc phasic firing, linear regression analyses were completed that correlated Signal-to-baseline (S:B) ratios for peak dopamine concentration $[D A]$ versus $S: B$ ratios for peak changes in NAc cell firing across cell types. Baseline for mean cell firing or rapid dopamine release was defined as the $10 \mathrm{~s}$ period before cue onset. Signal for cell firing and dopamine release was defined as $2 \mathrm{~s}$ after cue onset or lever press response. $S: B$ ratios were determined by dividing the signal by the baseline values. Finally, $\chi^{2}$ tests were used to examine differences in the number of neuronal cell types across the core and shell.

Histology. After each experiment, rats were deeply anesthetized with a ketamine $(100 \mathrm{mg} / \mathrm{kg}) /$ xylazine $(20 \mathrm{mg} / \mathrm{kg})$ intramuscular mixture. For the first and last experiment recording wire tips were marked by passing current $(13.5 \mu \mathrm{A}, 5 \mathrm{~s})$ through all the wires. Animals were then transcardially perfused with saline, than $10 \%$ formalin and $3 \%$ potassium ferrocyanide. For combined electrochemistry/electrophysiology experiment a tungsten electrode was lowered into the locations where recording had been made using a locally constructed microdrive. A 50-500 $\mu$ A current was passed through a stainless steel electrode for $5 \mathrm{~s}$ to mark the position of the electrode tip; multiple lesions were made when multiple recoding had been done. Rats were then perfused with saline and $10 \%$ formalin. Each brain was removed and, after postfixing and freezing, sliced into 40 $\mu \mathrm{m}$ coronal sections. Sections were then mounted on slides and stained with potassium ferrocyanide and counterstained with thionin to visualize electrodes tips as previously described (Roitman et al., 2005).

\section{Results}

Distinct populations of NAc neurons selectively encode information about the reward predictive cue and sucrose-reinforced response

All animals performed the task on the recording day, completing 60 trials with mean lever press response latencies of $0.36 \pm 0.05 \mathrm{~s}$ (time from lever out to press). A total of 79 cells ( $n=10$ rats) were recorded during the behavioral task in Experiment 1 (Table 1). Fifty-three neurons (67\%) displayed significant changes in firing rate relative to onset of the audio-visual cue and/or completion of the lever press, illustrated in the PEHs in Figure 2. Some neurons $(n=12$ cells) showed an increase in activity at cue onset (Fig. $2 A)$, classified as type CE. The majority of CE neurons increased their firing rates within $200 \mathrm{~ms}$ after cue onset to a peak of $3.1 \pm$ $0.5 \mathrm{~Hz}$ and returned to precue levels $3.2 \pm 0.5 \mathrm{~s}$ later. Of the $12 \mathrm{CE}$ neurons, 5 showed a further transient excitatory response to the lever press (Fig. $2 \mathrm{~A}$, inset). For those cells, an increase in firing rate to $8 \pm 1.9 \mathrm{~Hz}$ was observed within $1 \pm 0.5 \mathrm{~s}$ after cue onset, followed by a second peak of $11 \pm 2.7 \mathrm{~Hz}$ immediately after the lever press, and a return to baseline $4 \pm 0.3 \mathrm{~s}$ later. A second population of cells $(n=13)$ showed an inhibition in firing rate at cue onset (Fig. $2 \mathrm{~B}$ ), classified as type CI. Across all CI type cells, a decrease in firing rate was observed within $600 \pm 200 \mathrm{~ms}$ after cue onset (minimum rate of $1.8 \pm 0.5 \mathrm{~Hz}$ ). Cell firing returned to baseline levels $3.7 \pm 0.5$ s later.

Other NAc neurons were primarily active following the lever press for sucrose. A subset of these neurons $(n=13)$ displayed an increase in firing rate within seconds following the sucrosereinforced response (Fig. 2C; RE). For the majority of RE cells $(n=7)$, firing rate peaked to $5.9 \pm 2.3 \mathrm{~Hz}$ within $1.4 \pm 0.7 \mathrm{~s}$ following the lever press, returning to preresponse baseline levels $\sim 8$ s later. A subset of RE neurons $(n=6)$ showed a transient increase in activity characterized by a brief excitatory burst (peak: $4 \pm 0.8 \mathrm{~Hz}$ ) within $1.0 \pm 0.3 \mathrm{~s}$ after the press with a return to baseline $\sim 2$ s later (Fig. $2 C$, inset). A fourth subset of NAc neu-
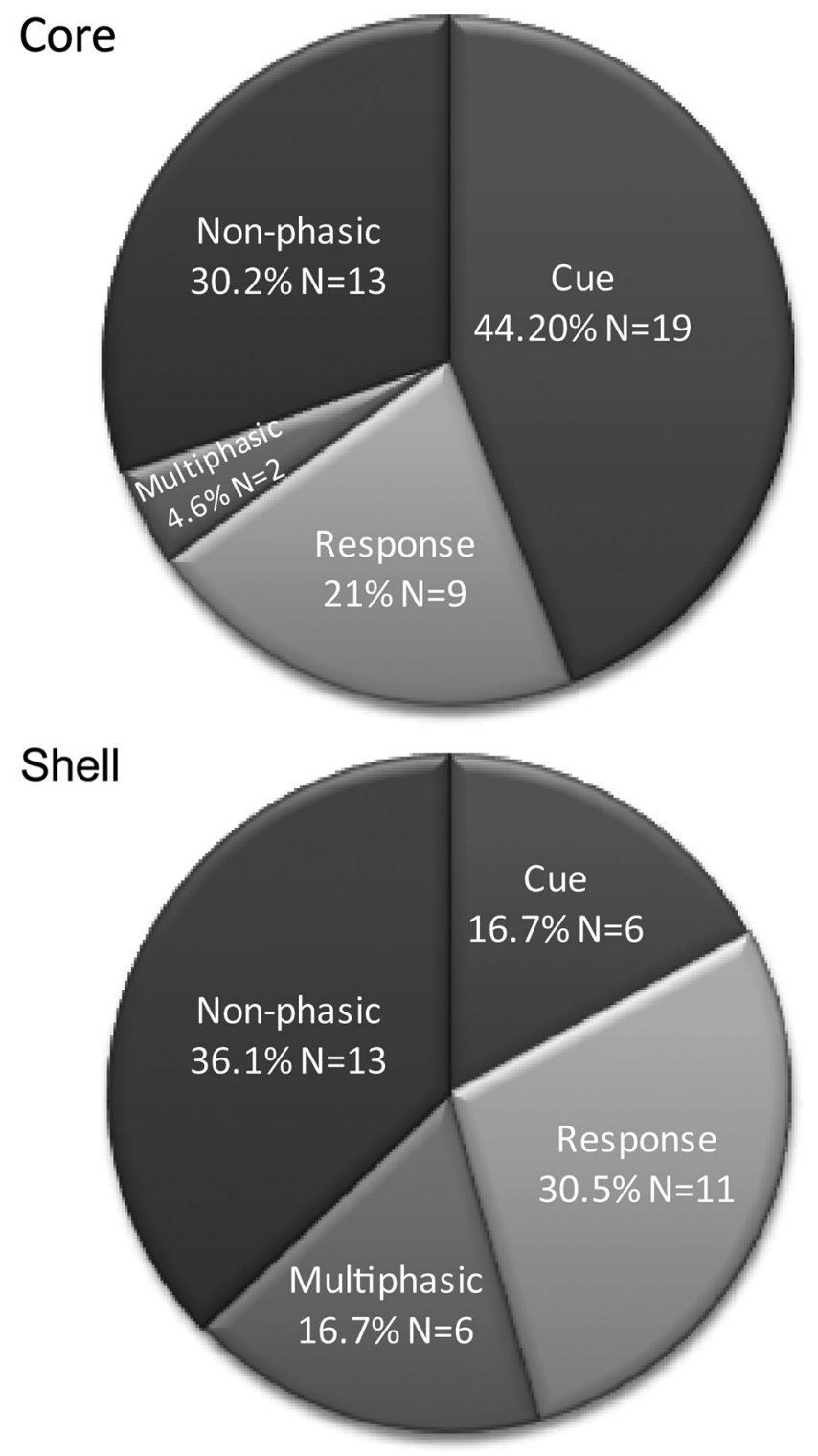

Figure 4. Composite pie charts showing the number and percentage of NAc neurons exhibiting different types of patterned discharges across the NAc core (top) and shell (bottom). Cue includes all type CE and type CI neurons; Response includes all type RE and type RI neurons; Multiphasic includes all type CE + RI and type Cl + RE neurons. Non-phasic (type NP) includes all NAc neurons that exhibited no change in firing rate relative to cue onset or the lever press.

rons $(n=7)$ displayed an inhibition in firing rate following the press (Fig. $2 D$; type RI). Across all RI cells, a decrease in firing rate was observed within $600 \pm 200 \mathrm{~ms}$ after the lever press that declined to a minimum rate of $1.9 \pm 0.8 \mathrm{~Hz}$. Activity returned to preresponse levels $4 \pm 1.5 \mathrm{~s}$ later. Importantly, cells types were not mutually exclusive across cue and operant events (i.e., for example, some CE neurons also displayed RE activity).

Other NAc neurons $(n=8)$ were classified as 'multiphasic' (Fig. 3) characterized by dual patterns of cell firing. One subset of cells $(n=4)$ exhibited an excitation to the predictive cue followed by an inhibition at the lever press/reward retrieval (termed CE+RI; Fig. 3A). CE+RI neurons displayed a peak firing rate of $7.2 \pm 1.2 \mathrm{~Hz}$ within $1 \pm 0.5 \mathrm{~s}$ of cue onset, then decreased activity to $1.2 \pm 0.6 \mathrm{~Hz} 1.9 \pm 0.6 \mathrm{~s}$ after the lever press with a return to baseline $2 \mathrm{~s}$ later. Other multiphasic neurons $(n=4)$ showed an inhibition in firing rate relative to cue onset followed by an excitation at the press/reward retrieval (CI+RE, Fig. 3B). CI+RE cells 
exhibited a decrease in firing rate to $0.7 \pm$ $0.3 \mathrm{~Hz} 1.6 \pm 0.2 \mathrm{~s}$ after cue onset, then increased firing within $200 \mathrm{~ms}$ after the lever press with a mean peak of $8.7 \pm 2.9 \mathrm{~Hz}$ that occurred $4.4 \pm 0.5 \mathrm{~s}$ after the response.

The remaining 26 neurons (33\% of total) showed no significant changes in firing rate relative to cue onset or the lever press response for sucrose, termed 'nonphasic.' The pie charts in Figure 4 show the distribution of cell types across the NAc core and shell. A $\chi^{2}$ test revealed significantly more neurons responsive to the cue in the core compared with the shell $\left(\chi^{2}\right.$ $=6.89, p<0.05)$. No significant differences were observed in the distribution of the other cell types across the core and shell.

\section{Coincident changes in NAc patterned cell firing and rapid dopamine release during behavior}

Next, we applied a combined electrochemistry/electrophysiology methodology in another group of rats to determine whether dopamine release events and NAc phasic cell firing are coincident at particular locations when simultaneously measured from the same electrode during the sucrose self-administration task. All animals $(n=14)$ performed the task on the recording day, with mean lever press response latencies of $0.38 \pm 0.06 \mathrm{~s}$. Recordings were made at 22 sites (13 in the shell and 9 in the core) where single units were isolated and stimulated dopamine release was measured before the start of the experiment (Table 1). Of 22 recordings, 18 neurons exhibited patterned discharges while 4 displayed non-phasic activity. The rasters and PEHs in Figure 5 show examples of simultaneously measured NAc cell firing and rapid dopamine release from the same location during the task. As is readily apparent, similar types of neuronal firing patterns were observed using the carbon fiber microelectrode versus multineuron stainless steel electrodes (Figs. 2, 3). Importantly, locations at which NAc cells displayed patterned changes were the same locations at which rapid dopamine release was present (Fig.

$5 A-E)$. For example, at the location where a type CE cell was recorded (Fig. 5A), a significant increase in dopamine concentration was observed immediately after cue onset (maximum $43 \mathrm{~nm}$ at $1.3 \pm$ $0.3 \mathrm{~s}$ after the cue onset; $p<0.05$ compared with baseline) which declined at the lever press. The population analysis for the two CE cells recorded showed a peak increase in cell firing of $4.6 \pm 0.06 \mathrm{~Hz}$ at following cue onset, lasting $3.4 \pm 0.2 \mathrm{~s}$ after cue presentation. On average, dopamine increased immediately upon cue presentation and reached a maximal concentration of $48.7 \pm 5.7 \mathrm{~nm}$ following the cue $(p<0.05$ compared with baseline).

At a discrete location where a type CI cell was recorded (Fig. $5 B)$, cue-evoked dopamine release reached a maximum of $46 \mathrm{~nm}$
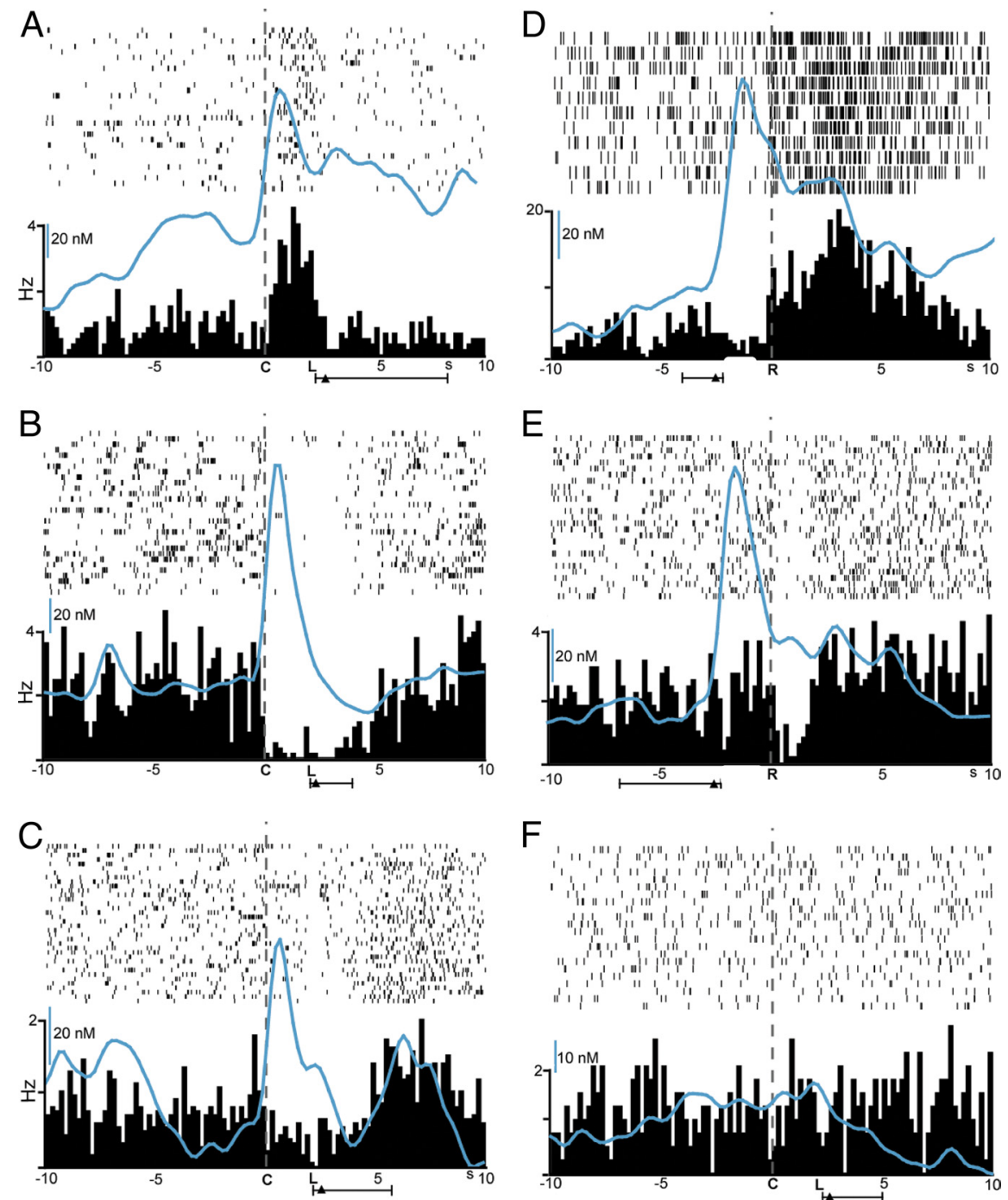

Figure 5. Combined electrochemical and electrophysiological recordings in the NAc during the task. Rasters and PEHs show NAc cell firing for individual neurons aligned to cue onset (left, C) or the lever press (right, R). Dopamine concentration at each location was determined by principal component analysis and is shown as a blue trace superimposed on each raster/PEH. $\boldsymbol{A}$, Type CE neuron in firing rate at cue onset coincident with a peak in dopamine concentration. $\boldsymbol{B}$, Type $\mathrm{Cl}$ cell showed an inhibition in activity at cue onset that coincided with a rapid raise in cue-evoked dopamine release. $C$, Type $\mathrm{Cl}+\mathrm{RE}$ neuron exibited an inhibition at cue onset and an excitation $\sim 5$ s later with coincident changes in rapid dopamine release. D, Type RE cell showed an excitation in activity after the lever press; the increase in dopamine concentration peaked seconds before the response and remained elevated for $\sim 5$ slater. $\boldsymbol{E}$, Type RI cells display an inhibition in firing at the response while dopamine peaked seconds dopamine release events are observed at this location. $\boldsymbol{A}-\boldsymbol{C}, \boldsymbol{F}$, Data are aligned to cue onset ( $\boldsymbol{C}$, at time 0$)$. L, Lever extension. The average time of latency to lever press is denoted by the black triangle, and the range of times is represented by the horizontal scale bar. $\boldsymbol{D}, \boldsymbol{E}$, Data are aligned to lever press response ( $R$, at time 0$)$. The average time of cue onset is denoted by the black triangle, and the range of times is represented by the horizontal scale bar.

( $p<0.05$ compared with baseline) after the cue onset; increases in dopamine concentration and inhibition of cellular activity were synchronized and time locked to cue onset. Across all CI cells in this combined electrophysiology/electrochemistry study $(n=8)$, an inhibition in firing began $0.6 \pm 0.13 \mathrm{~s}$ after cue onset, declining from $2.7 \pm 0.7 \mathrm{~Hz}$ to $0.6 \pm 0.3 \mathrm{~Hz}(p<0.05)$. At the same sites at which CI neurons were recorded, the dopamine concentration maximum was $36.1 \pm 4.3 \mathrm{~nm}(p<0.05$ compared with baseline) $0.9 \pm 0.1 \mathrm{~s}$ after cue onset.

Of the two types of multiphasic neurons recorded in the first study (Fig. 3$)$, only type CI+RE $(n=2)$ was observed here (Fig. $5 C)$. For these cells, an inhibition in cell firing occurred within 
$200 \mathrm{~ms}$ after cue onset followed by an increase in firing rate $\sim 2 \mathrm{~s}$ after the lever press. Dopamine concentration increased after cue onset (maximum increase of $34 \mathrm{~nm} ; p<0.05$ compared with baseline) with a second increase within seconds after the lever press (maximum increase of $18 \mathrm{~nm}$ ).

Likewise, rapid dopamine signaling was observed at locations where type RE neurons were recorded. For the example shown in Figure $5 D$, the RE cell exhibited a significant increase in cell firing from baseline levels immediately after the lever press and remained elevated for $\sim 8 \mathrm{~s}$. At this same location, dopamine concentration increased seconds before cue onset and reached a maximum of $125 \mathrm{~nm}$ ( $p<0.05$ compared with baseline) before the response, with a second increase in dopamine that peaked at $64 \mathrm{nM}$ within $\sim 3$ s of the lever press. Across the two RE cells recorded, an excitation in firing began at $0.1 \pm 0.1 \mathrm{~s}$ after the lever press and lasted $8 \pm 2 \mathrm{~s}$. At the same sites at which RE neurons were recorded, the dopamine concentration maxima was $90.5 \pm$ $34.6 \mathrm{~nm}(p<0.05$ compared with baseline) $1.4 \pm 0.6 \mathrm{~s}$ after the cue onset. Other NAc cells $(n=4)$ displayed type RI activity, as illustrated for this cell in Figure 5E. At the same location, dopamine concentration increased to a maximum of $47.3 \mathrm{~nm}$ at cue onset. Importantly, locations at which neurons exhibited nonphasic activity (no change in firing rate relative to cue presentation or the lever press, $n=4$ cells), no significant changes in rapid dopamine signaling were observed (Fig. $5 F$ ).

To further examine the relationship between rapid dopamine release and NAc phasic firing, linear regression analyses were completed that correlated $S: B$ ratios for peak [DA] versus $S: B$ ratios for peak changes in NAc cell firing across cell types. For neurons that displayed increases in cell firing relative to cue onset or the lever press (types CE, RE, and the excitatory response of $\mathrm{CI}+\mathrm{RE}$ cells), a significant positive linear regression was observed between S:B [DA] and S:B cell firing $\left(F_{(1,4)}=7.73, p<\right.$ $0.05, r^{2}=0.66$; Fig. $6 A$ ). In contrast, for neurons that displayed decreases in cell firing relative to cue onset or the lever press (types $\mathrm{CI}, \mathrm{RI}$, or the inhibitory response of $\mathrm{CI}+\mathrm{RE}$ cells) the correlation was not significant between S:B [DA] and S:B cell firing $\left(F_{(1,13)}=1.93, p=0.2, r^{2}=0.13\right.$; Fig. $\left.6 B\right)$.

\section{Burst firing of VTA dopamine neurons differentially} modulates NAc patterned activity depending on cell type The previous study revealed that, at the majority of locations, coincident patterned cell firing and phasic dopamine release was observed relative to reward predictive cues and/or lever press responding for sucrose. A critical question however is whether there is a causal link between the two events. To examine this issue, we incorporated microinjection of an NMDA receptor antagonist (AP-5), shown to selectively decrease burst firing of VTA dopamine neurons (Chergui et al., 1993) and rapid dopamine signaling in the NAc (Sombers et al., 2009) in conjunction with electrophysiological recording.

A total of 45 cells ( $n=9$ rats) were recorded ( 25 cells in the shell, 20 in the core) during the task (Table 1). The PEHs in Figure 7 show population histograms for all NAc neurons recorded ipsilateral to injection sites before (black PEHs) versus following (red lines) VTA inactivation. Twenty neurons displayed changes in firing relative to the presentation of the audiovisual cue and/or the sucrose reinforced response. Neurons exhibiting significant increases in cell firing relative to the cue or lever press were attenuated by VTA inactivation. Figure $7 A$ shows that type CE neurons $(n=6)$ increased firing immediately after cue onset and returned to baseline levels $\sim 3$ s later before drug treatment. Microinjection of AP-5 into the VTA significantly attenuated type CE activ-
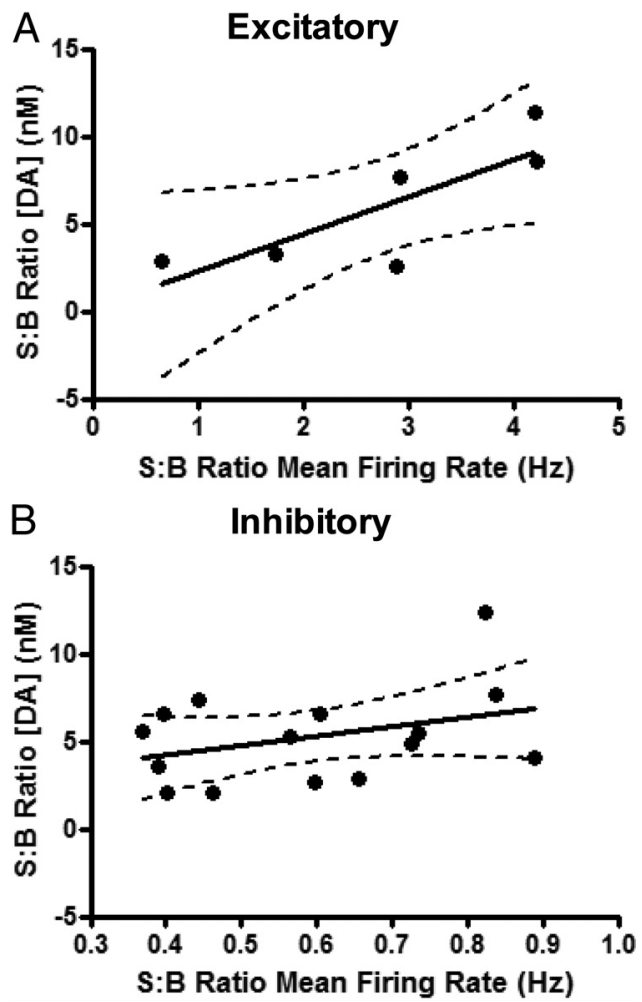

Figure 6. Linear regression analyses correlating $S: B$ ratios for peak $[D A]$ versus $S: B$ ratios for peak changes in NAc cell firing across cell types. $A$, For neurons displaying increased firing rate to cue onset or the lever press (types $\mathrm{CE}, \mathrm{RE}$, and the excitatory response of $\mathrm{Cl}+\mathrm{RE}$ cells), a significant positive linear regression was observed. $\boldsymbol{B}$, For neurons displaying decreased firing rate to cue onset or the lever press (types $\mathrm{Cl}, \mathrm{Rl}$, or the inhibitory response of $\mathrm{Cl}+\mathrm{RE}$ cells), the correlation was not significant.

ity $\left(F_{(9,45)}=2.4, p<0.05\right)$. Tukey's post hoc test revealed a significant attenuation in NAc cell firing from 1 to $3 \mathrm{~s}$ following cue onset after AP-5 treatment. Although there was a small reduction in baseline firing rate this was not significant $(p>0.05)$. Inactivation of VTA dopamine neuron burst-firing also affected the excitatory response of type RE cells $(n=5$; Fig. $7 B)$. Predrug recording shows an increase in firing rate immediately after the lever press for sucrose that was attenuated after the infusion of AP-5 without any change in baseline firing $\left(F_{(9,36)}=4.83, p<\right.$ $0.0005)$. Tukey's post hoc test revealed a significant reduction in cell firing following AP-5 treatment from 1 to $7 \mathrm{~s}$ after the lever press response.

Interestingly, the inactivation of VTA burst firing did not affect the patterned cell firing of NAc neurons that exhibited an inhibitory response profile relative to either cue onset (type CI) or the lever press/reward (type RI). Figure $7 C$ shows that the firing rate of CI neurons $(n=4)$ significantly decreased $600 \mathrm{~ms}$ after the cue onset during the predrug session and that AP-5 microinjection did not affect this activity $\left(F_{(9,27)}=1.23, p=\right.$ $0.32)$. Likewise, type RI patterned cell firing $(n=5)$ was unaffected by the NMDA antagonist. Figure $7 D$ shows that before AP-5 injection RI neurons exhibited a decrease in firing rate $\sim 400 \mathrm{~ms}$ after the lever press. Pharmacological inactivation of the VTA did not affect this inhibition $\left(F_{(9,36)}=0.85, p=0.57\right)$.

Of the two types of multiphasic neurons recorded in first experiment (Fig. 3), only type CI+RE was observed here $(n=5$; Fig. 7E). This cell type exhibited an inhibition in firing rate immediately after cue onset followed by an excitation at the lever press. A three-way ANOVA revealed a significant bin $\times$ re- 
sponse $\times$ drug interaction $\left(F_{(9,36)}=2.66\right.$, $p<0.05)$. Tukey's post hoc analysis revealed that microinjection of AP-5 into the VTA did not affect the cue inhibitory response profile but attenuated the excitatory response to the sucrose-reinforced lever press $(p<0.05)$. Importantly, inactivation of VTA dopamine neuron burst firing did not cause any change in neuronal firing rates at the location where non-phasic cells $(n=11)$ were recorded (Fig. $7 F$ ).

Electrophysiological recordings were performed on both sides of the brain with the hemisphere contralateral to the AP-5 injection used as the control site $(n=9)$. Figure 8 shows patterned cell firing of neurons recorded on the control side that displayed an excitatory (type CE, Fig. $8 A$ ) or inhibitory (type CI, Fig. $8 B$ ) response profile. Two-way ANOVAs revealed no significant affect of AP-5 inactivation on both $\mathrm{CE}\left(F_{9,36}=2.12, p>0.05\right)$ and $\mathrm{CI}$ $\left(F_{9,27}=0.96, p>0.05\right)$ neuronal activity.

Finally, we examined the average latency to press the lever following VTA inactivation with AP-5 compared with microinfusion of saline to determine whether the goal-directed action was affected by drug treatment. All animals performed the task following saline or drug treatment although there were significant differences in response latencies. Specifically, the average latency to lever press for sucrose was significantly increased after microinfusion of AP-5 (latency $=0.95 \pm 0.16$ ) relative to saline (latency $=0.38 \pm 0.05$ ) $\left.t_{(8)}=4.3, p<0.05\right)$.

\section{Histological verification of} electrode/cannula placements

Histological examination of electrode tip placements revealed that microelectrode arrays and carbon fiber electrodes were situated in the NAc core or shell for all data included in this report (Fig. 9A-C).

Histological examination of cannula tip placements included in the final study were located in the VTA (Fig. 9D) In rats with misplaced cannulae $(n=2$, one in the hypothalamus and one in the substantia nigra), AP-5 did not have any effect on behavior or NAc cell firing (data not shown) and were not included in the present study.

\section{Discussion}

We show that rapid dopamine signaling occurs with the same temporal resolution as NAc patterned cell firing and the two events are coincident during goal-directed actions for sucrose. Specifically, locations at which NAc neurons encode discrete aspects of sucrose-directed behaviors were the same places that phasic dopamine signaling was observed. These findings are consistent with previous reports with other rewards (Cheer et al., 2005, 2007; Owesson-White et al., 2008) and support the view that dopamine functions as a neuromodulator, influencing the
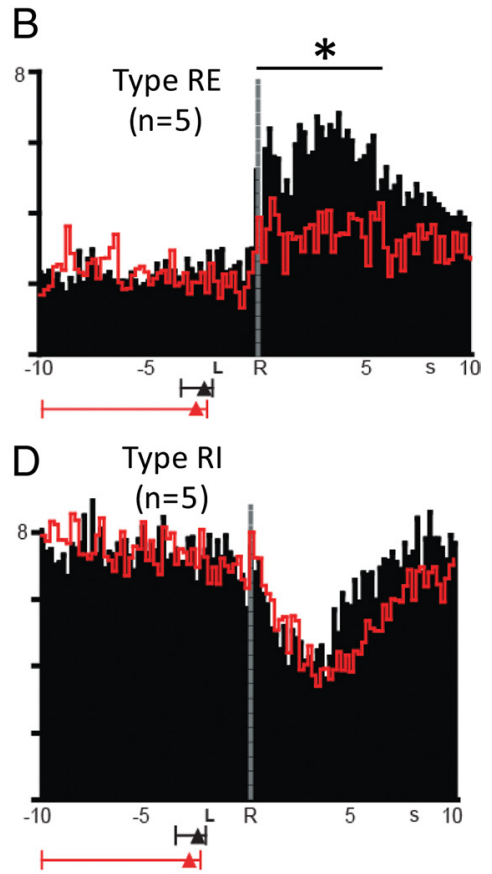

$\mathrm{F}$

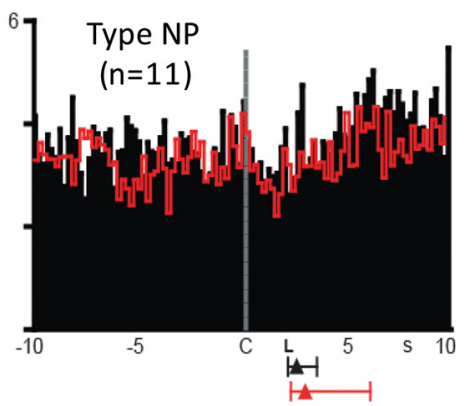

Figure 7. Effects of VTA inactivation on NAc neuronal activity across cell types. Population PEHs show neuronal activity after (a) saline microinfusion into the VTA. Red lines represent activity of the same neurons following unilateral AP-5 microinfu列 列 onset is denoted by the triangles (saline, black; AP-5, red), and the range of times is represented by the horizontal scale bars (saline, black; AP-5, red). Note VTA inactivation selectively attenuated excitatory (but not inhibitory) response profiles to the cue or lever press without significantly altering baseline firing rates.

activation of NAc neurons by specific excitatory afferents (Pennartz et al., 1994; Carelli and Wightman, 2004). It is well known that NMDA receptors influence burst firing of dopamine neurons (Overton and Clark, 1992; Suaud-Chagny et al., 1992; Chergui et al., 1993; Deister et al., 2009). To determine causality, we recorded NAc cell firing during the task after pharmacological inactivation of the VTA using AP-5, an NMDA receptor antagonist shown to selectively inactivate dopamine burst firing (Chergui et al., 1993), the origins of rapid dopamine signaling in the NAc (Sombers et al., 2009). Interestingly, inactivation of VTA burst firing did not result in a generalized reduction of NAc activity, but instead altered cell firing of select populations of NAc neurons that encode specific aspects of the task. Neurons that exhibited an excitation in cell firing relative to cue presentation or the operant response showed an elimination of this phasic response following inactivation. In contrast, cells that displayed an inhibition in cell firing at cue onset and/or the press were not 
A
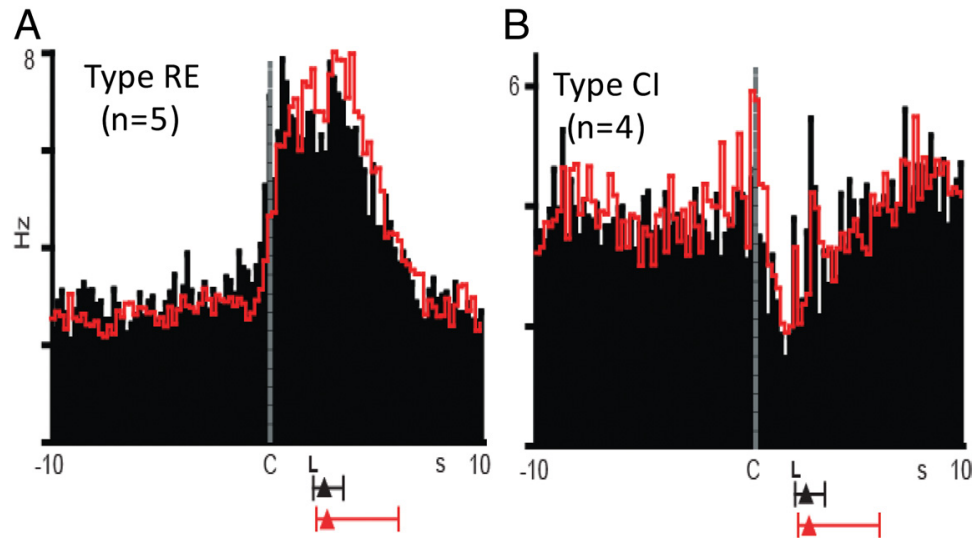

Figure 8. VTA inactivation did not affect NAc neuronal activity when injected on the contralateral (control) side for type RE $(\boldsymbol{A})$ and type $\mathrm{Cl}(\boldsymbol{B})$ cells. Data are aligned to cue onset (C, at time 0$)$. L, Lever extension.
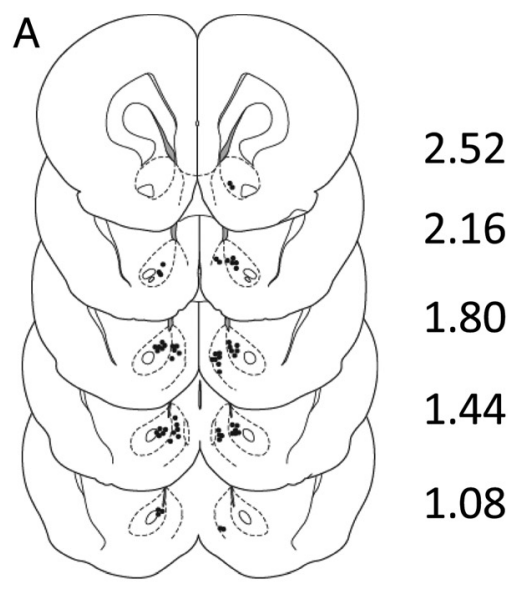

1.80

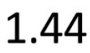

1.08
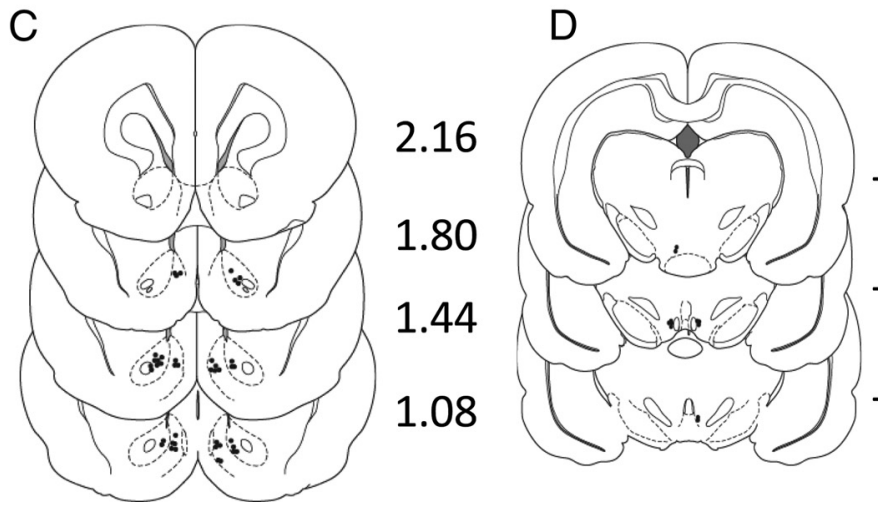

1.80

1.44

1.08

B

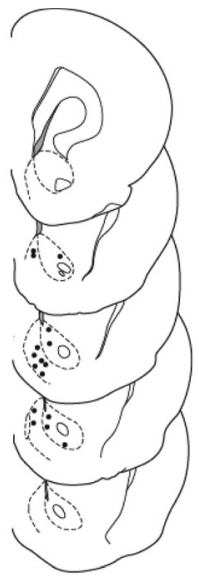

2.52

2.16

1.80

1.44

1.08

Figure 9. $\boldsymbol{A}$, Coronal diagram illustrating confirmed location of microwire tip placements for experiment 1 within the NAc shell and core. $\boldsymbol{B}$, Distribution of carbon-fiber microelectrodes in the NAC shell and core for experiment 2. $C, D$, Distribution of microelectrodes in the NAc shell and core $(\boldsymbol{C})$ and guide cannulae tips in the VTA $(\boldsymbol{D})$ for experiment 3. Numbers to the right indicate the anteroposterior coordinates ( $\pm 0.2 \mathrm{~mm}$ ) relative to bregma. Coordinates and drawings were taken from a stereotaxic atlas (Paxinos and Watson, 2005).

affected by VTA inactivation. In fact, for neurons that exhibited both excitatory and inhibitory response profiles, only excitatory activity was attenuated by AP-5. Further, a significant correlation was observed between $\mathrm{S}: \mathrm{B}[\mathrm{DA}]$ and $\mathrm{S}: \mathrm{B}$ cell firing for neurons displaying an excitation in activity relative to the cue and/or response, but not for neurons showing an inhibition during those events. Finally, AP-5 did not cause a significant reduction in baseline activity of any NAc cell type, underscoring the selective na-
$-4.80$

ture of dopamine modulation of NAc neuronal activity during behavior.

A critical issue to consider is how rapid dopamine release from the VTA can selectively modulate specific subsets of NAc neurons while leaving other cells unaffected. One mechanism may be related to the bistable membrane potential properties (O'Donnell, 2003; Surmeier et al., 2007). It has been shown that dopamine facilitates 'up states' while simultaneously reducing firing rate of striatal cells (Goto and O'Donnell, 2001). Such action increases the signal-to-baseline ratio of phasically active NAc neurons thereby resulting in stronger efferent signals. Further, distinct subsets of striatal (Surmeier et al., 2007) and accumbal (Hasbi et al., 2010) neurons differentially express D1 versus D2 receptors. In fact, only $25 \%$ of NAc neurons coexpress both receptor subtypes in the adult rat NAc (Hasbi et al., 2010). When dopamine levels reach high concentrations for brief periods (i.e., due to phasic release), low affinity D1 receptors are activated (Richfield et al., 1989) while tonic dopamine levels are believed to chronically occupy D-2 like high affinity receptors on NAc neurons (Kawagoe et al., 1992). Further, the transition of dopamine activity from tonic to burst firing leads to a lower occupancy of dopamine D2 compared with D1 receptors (Dreyer et al., 2010) suggesting that blocking VTA burst firing would not significantly alter D2 receptor activation. Thus, the activation of specific subsets of NAc neurons may be related in part, to the type of dopamine receptor located on them (Wickens and Wilson, 1998; Surmeier et al., 2007; Shen et al., 2008).

Further, dopamine neurons have axons that arborize, resulting in terminals that are clustered in multiple locations (Prensa and Parent, 2001). Burst firing of dopamine neurons within this anatomical organization results in high dopamine concentrations that occurs relatively ubiquitously; even at locations where dopamine makes synaptic contact with NAc cells that display inhibitory response profiles. As noted above, we postulate that AP-5, by selectively blocking burst firing of dopamine neurons reduces phasic dopamine release that may normally mediate the excitatory profile of particular NAc neurons, perhaps through bistable membrane potentials of those MSNs via dopamine D1 receptors located on those cells. Tonic dopamine remains present at high enough levels to activate D2-high affinity receptors that may be partly responsible for inhibitory firing patterns along with the inhibitory neurotransmitter GABA that is present via local connections on subsets of neurons in the NAc (Pennartz et al., 1994) or through complex actions of fast-spiking 
GABAergic interneurons (Berke, 2008). These findings are consistent with our previous studies showing that the firing of NAc neurons that displayed an inhibitory response to electrical stimulation of the medial forebrain bundle (MFB) was not altered by vesicular dopamine depletion but was reversed to an excitatory response profile following blockade of $\mathrm{GABA}_{\mathrm{A}}$ receptors (Cheer et al., 2005).

The present findings appear somewhat inconsistent with a report by Yun and colleagues (Yun et al., 2004) in which NAc cell firing was recorded during a cued operant (nose poke) task following VTA inactivation with a GABA-B agonist, baclofen. In that study, baclofen blocked both excitatory and inhibitory firing evoked by incentive cues. However, a significant reduction in baseline cell firing rates was also observed that was not the case in the present study. The discrepancy in that report and the present findings may be due to differences in the inactivation properties by AP- 5 versus baclofen. That is, while AP- 5 selectively attenuates burst firing of VTA neurons, baclofen likely affects both phasic and tonic discharges (Olpe et al., 1977; Lacey et al., 1988; Johnson and North, 1992; Erhardt et al., 2002). In the absence of both tonic and phasic dopamine, neither D1 nor D2 receptors can be activated. This generalized inactivation may explain the shift in baseline cell firing and the attenuation in activity to incentive stimuli following baclofen treatment. Interestingly, Yun and colleagues also reported that VTA baclofen administration did not alter neural firing rates relative to the operant response for sucrose. Again, this contrasts with the present study (where excitatory activity that occurred immediately following the response was reduced by AP-5) and may also be related to the generalized reduction in VTA cell firing (both tonic and phasic) that occurs with baclofen but not AP-5.

However, mechanisms underlying the encoding of cue and reward-seeking behaviors by NAc neurons likely extend beyond the NAc and encompass a larger neural circuit in which this structure is embedded. In an operant task in which animals must respond quickly for reward, phasic dopamine likely functions to modulate the responsiveness of distinct subsets of NAc neurons governed by their unique afferent and efferent connections (Mogenson et al., 1980; Pennartz et al., 1994; Nicola et al., 2000; Carelli and Wightman, 2004). Interestingly, we observed some differences in cell firing properties and rapid dopamine release across the core and shell of the NAc, although it is important to note we are not able to distinguish whether postresponse activity is related to the lever press or reward consumption. Regardless, activation of NAc neurons by cues signaling impending lever extension was greater in the core than shell (Fig. 4), consistent with a role of the NAc core in encoding cue-reward associations (Parkinson et al., 1999, 2002; Ito et al., 2000, 2004; Di Ciano and Everitt, 2001; Fuchs et al., 2004). Rapid dopamine release was observed in both NAc subregions; ongoing studies are further examining whether more subtle differences exist in the timing of dopamine signaling across subregions as was the case in prior studies (Aragona et al., 2009). Nevertheless, the present findings highlight the complex microcircuit in the NAc that dopamine functions within to modulate goal-directed behavior.

The behavioral significance of rapid dopamine signaling the NAc is evident from VTA inactivation by AP- 5 in our last study. In this case, unilateral, intra-VTA microinfusion of AP-5 produced a significant increase in the average latency to lever press following cue presentation, compared with microinfusion of saline. The attenuation of behavioral responding reported here is consistent with the notion that dopamine transients in the NAc drive goal-directed behavior for natural reward (Roitman et al.,
2004; Jones et al., 2010). Likewise, intra-VTA AP-5 has been shown to produce a significant decrease in cue-evoked dopamine release and increase in latency to lever press during ICSS (Sombers et al., 2009) also consistent with the present findings.

The critical finding of the present study is that rapid dopamine signaling does not exert uniform global actions across all NAc neurons, but instead modulates the activity of discrete populations of NAc cells likely depending upon cell type, receptor type, location, afferent/efferent connectivity, reward type, meaningful environmental cues and ongoing goal-directed behaviors. Further, the actions of phasic (rapid) dopamine release events appear dissociable from tonic effects and likely modulate distinct aspects of NAc neural signaling within local circuits, as well as by specific NAc afferents. Dissecting the precise neural activation of discrete NAc microcircuits by rapid dopamine signaling during behavior thereby provides unique insight into the complex role of dopamine in modulating reward.

\section{References}

Aragona BJ, Day JJ, Roitman MF, Cleaveland NA, Wightman RM, Carelli RM (2009) Regional specificity in the real-time development of phasic dopamine transmission patterns during acquisition of a cue-cocaine association in rats. Eur J Neurosci 30:1889-1899.

Berke JD (2008) Uncoordinated firing rate changes of striatal fast-spiking interneurons during behavioral task performance. J Neurosci 28: 10075-10080.

Carelli RM (2000) Activation of accumbens cell firing by stimuli associated with cocaine delivery during self-administration. Synapse 35:238-242.

Carelli RM (2002) Nucleus accumbens cell firing during goal-directed behaviors for cocaine vs 'natural' reinforcement. Physiol Behav 76:379-387.

Carelli RM, Wightman RM (2004) Functional microcircuitry in the accumbens underlying drug addiction: insights from real-time signaling during behavior. Curr Opin Neurobiol 14:763-768.

Carelli RM, King VC, Hampson RE, Deadwyler SA (1993) Firing patterns of nucleus accumbens neurons during cocaine self-administration in rats. Brain Res 626:14-22.

Carelli RM, Ijames SG, Crumling AJ (2000) Evidence that separate neural circuits in the nucleus accumbens encode cocaine versus "natural" (water and food) reward. J Neurosci 20:4255-4266.

Cheer JF, Heien ML, Garris PA, Carelli RM, Wightman RM (2005) Simultaneous dopamine and single-unit recordings reveal accumbens GABAergic responses: implications for intracranial self-stimulation. Proc Natl Acad Sci U S A 102:19150-19155.

Cheer JF, Aragona BJ, Heien ML, Seipel AT, Carelli RM, Wightman RM (2007) Coordinated accumbal dopamine release and neural activity drive goal-directed behavior. Neuron 54:237-244.

Chergui K, Charléty PJ, Akaoka H, Saunier CF, Brunet JL, Buda M, Svensson TH, Chouvet G (1993) Tonic activation of NMDA receptors causes spontaneous burst discharge of rat midbrain dopamine neurons in vivo. Eur J Neurosci 5:137-144.

Day JJ, Wheeler RA, Roitman MF, Carelli RM (2006) Nucleus accumbens neurons encode Pavlovian approach behaviors: evidence from an autoshaping paradigm. Eur J Neurosci 23:1341-1351.

Day JJ, Roitman MF, Wightman RM, Carelli RM (2007) Associative learning mediates dynamic shifts in dopamine signaling in the nucleus accumbens. Nat Neurosci 10:1020-1028.

Deister CA, Teagarden MA, Wilson CJ, Paladini CA (2009) An intrinsic neuronal oscillator underlies dopaminergic neuron bursting. J Neurosci 29:15888-15897.

Di Ciano P, Everitt BJ (2001) Dissociable effects of antagonism of NMDA and AMPA/KA receptors in the nucleus accumbens core and shell on cocaine-seeking behavior. Neuropsychopharmacology 25:341-360.

Dreyer JK, Herrik KF, Berg RW, Hounsgaard JD (2010) Influence of phasic and tonic dopamine release on receptor activation. J Neurosci 30:14273-14283.

Erhardt S, Mathé JM, Chergui K, Engberg G, Svensson TH (2002) GABA(B) receptor-mediated modulation of the firing pattern of ventral tegmental area dopamine neurons in vivo. Naunyn Schmiedebergs Arch Pharmacol 365:173-180.

Fuchs RA, Evans KA, Parker MC, See RE (2004) Differential involvement of 
the core and shell subregions of the nucleus accumbens in conditioned cue-induced reinstatement of cocaine seeking in rats. Psychopharmacology (Berl) 176:459-465.

Goto Y, O'Donnell P (2001) Network synchrony in the nucleus accumbens in vivo. J Neurosci 21:4498-4504.

Hasbi A, O'Dowd BF, George SR (2010) Heteromerization of dopamine D2 receptors with dopamine D1 or D5 receptors generates intracellular calcium signaling by different mechanisms. Curr Opin Pharmacol 10:93-99.

Heien ML, Khan AS, Ariansen JL, Cheer JF, Phillips PE, Wassum KM, Wightman RM (2005) Real-time measurement of dopamine fluctuations after cocaine in the brain of behaving rats. Proc Natl Acad Sci U S A 102:10023-10028.

Hollander JA, Carelli RM (2005) Abstinence from cocaine self-administration heightens neural encoding of goal-directed behaviors in the accumbens. Neuropsychopharmacology 30:1464-1474.

Ikemoto S (2007) Dopamine reward circuitry: Two projection systems from the ventral midbrain to the nucleus accumbens-olfactory tubercle complex. Brain Res Rev 56:27-78.

Ito R, Dalley JW, Howes SR, Robbins TW, Everitt BJ (2000) Dissociation in conditioned dopamine release in the nucleus accumbens core and shell in response to cocaine cues and during cocaine-seeking behavior in rats. J Neurosci 20:7489-7495.

Ito R, Robbins TW, Everitt BJ (2004) Differential control over cocaineseeking behavior by nucleus accumbens core and shell. Nat Neurosci 7:389-397.

Johnson SW, North RA (1992) Two types of neurone in the rat ventral tegmental area and their synaptic inputs. J Physiol 450:455-468.

Jones JL, Wheeler RA, Carelli RM (2008) Behavioral responding and nucleus accumbens cell firing are unaltered following periods of abstinence from sucrose. Synapse 62:219-228.

Jones JL, Day JJ, Aragona BJ, Wheeler RA, Wightman RM, Carelli RM (2010) Basolateral amygdala modulates terminal dopamine release in the nucleus accumbens and conditioned responding. Biol Psychiatry 67:737-744.

Kawagoe KT, Garris PA, Wiedemann DJ, Wightman RM (1992) Regulation of transient dopamine concentration gradients in the microenvironment surrounding nerve terminals in the rat striatum. Neuroscience 51:55-64.

Keithley RB, Carelli RM, Wightman RM (2010) Rank estimation and the multivariate analysis of in vivo fast-scan cyclic voltammetric data. Anal Chem 82:5541-5551.

Lacey MG, Mercuri NB, North RA (1988) On the potassium conductance increase activated by GABAB and dopamine $\mathrm{D} 2$ receptors in rat substantia nigra neurones. J Physiol 401:437-453.

Mogenson GJ, Wu M, Jones DL (1980) Locomotor activity elicited by injections of picrotoxin into the ventral tegmental area is attenuated by injections of GABA into the globus pallidus. Brain Res 191:569-571.

Nicola SM, Surmeier J, Malenka RC (2000) Dopaminergic modulation of neuronal excitability in the striatum and nucleus accumbens. Annu Rev Neurosci 23:185-215.

O’Donnell P (2003) Dopamine gating of forebrain neural ensembles. Eur J Neurosci 17:429-435.

Olpe HR, Koella WP, Wolf P, Haas HL (1977) The action of Baclofen on neurons of the substantia nigra and of the ventral tegmental area. Brain Res 134:577-580.

Overton P, Clark D (1992) Iontophoretically administered drugs acting at the $\mathrm{N}$-methyl-D-aspartate receptor modulate burst firing in A9 dopamine neurons in the rat. Synapse 10:131-140.

Owesson-White CA, Cheer JF, Beyene M, Carelli RM, Wightman RM (2008)
Dynamic changes in accumbens dopamine correlate with learning during intracranial self-stimulation. Proc Natl Acad Sci U S A 105:11957-11962.

Owesson-White CA, Ariansen J, Stuber GD, Cleaveland NA, Cheer JF, Wightman RM, Carelli RM (2009) Neural encoding of cocaine-seeking behavior is coincident with phasic dopamine release in the accumbens core and shell. Eur J Neurosci 30:1117-1127.

Parkinson JA, Olmstead MC, Burns LH, Robbins TW, Everitt BJ (1999) Dissociation in effects of lesions of the nucleus accumbens core and shell on appetitive pavlovian approach behavior and the potentiation of conditioned reinforcement and locomotor activity by D-amphetamine. J Neurosci 19:2401-2411.

Parkinson JA, Dalley JW, Cardinal RN, Bamford A, Fehnert B, Lachenal G, Rudarakanchana N, Halkerston KM, Robbins TW, Everitt BJ (2002) Nucleus accumbens dopamine depletion impairs both acquisition and performance of appetitive Pavlovian approach behaviour: implications for mesoaccumbens dopamine function. Behav Brain Res 137:149-163.

Paxinos G, Watson C (2005) The rat brain in stereotaxic coordinates. San Diego: Elsevier Academic.

Pennartz CM, Groenewegen HJ, Lopes da Silva FH (1994) The nucleus accumbens as a complex of functionally distinct neuronal ensembles: an integration of behavioural, electrophysiological and anatomical data. Prog Neurobiol 42:719-761.

Phillips PE, Stuber GD, Heien ML, Wightman RM, Carelli RM (2003) Subsecond dopamine release promotes cocaine seeking. Nature 422:614618.

Prensa L, Parent A (2001) The nigrostriatal pathway in the rat: a single-axon study of the relationship between dorsal and ventral tier nigral neurons and the striosome/matrix striatal compartments. J Neurosci 21:72477260 .

Richfield EK, Penney JB, Young AB (1989) Anatomical and affinity state comparisons between dopamine D1 and D2 receptors in the rat central nervous system. Neuroscience 30:767-777.

Roitman MF, Stuber GD, Phillips PE, Wightman RM, Carelli RM (2004) Dopamine operates as a subsecond modulator of food seeking. J Neurosci 24:1265-1271.

Roitman MF, Wheeler RA, Carelli RM (2005) Nucleus accumbens neurons are innately tuned for rewarding and aversive taste stimuli, encode their predictors, and are linked to motor output. Neuron 45:587-597.

Shen W, Flajolet M, Greengard P, Surmeier DJ (2008) Dichotomous dopaminergic control of striatal synaptic plasticity. Science 321:848-851.

Sombers LA, Beyene M, Carelli RM, Wightman RM (2009) Synaptic overflow of dopamine in the nucleus accumbens arises from neuronal activity in the ventral tegmental area. J Neurosci 29:1735-1742.

Suaud-Chagny MF, Chergui K, Chouvet G, Gonon F (1992) Relationship between dopamine release in the rat nucleus accumbens and the discharge activity of dopaminergic neurons during local in vivo application of amino acids in the ventral tegmental area. Neuroscience 49:63-72.

Surmeier DJ, Ding J, Day M, Wang Z, Shen W (2007) D1 and D2 dopaminereceptor modulation of striatal glutamatergic signaling in striatal medium spiny neurons. Trends Neurosci 30:228-235.

Wheeler RA, Twining RC, Jones JL, Slater JM, Grigson PS, Carelli RM (2008) Behavioral and electrophysiological indices of negative affect predict cocaine self-administration. Neuron 57:774-785.

Wickens JR, Wilson CJ (1998) Regulation of action-potential firing in spiny neurons of the rat neostriatum in vivo. J Neurophysiol 79:2358-2364.

Yun IA, Wakabayashi KT, Fields HL, Nicola SM (2004) The ventral tegmental area is required for the behavioral and nucleus accumbens neuronal firing responses to incentive cues. J Neurosci 24:2923-2933. 